\title{
Progress in Liver Transplantation
}

\author{
Charles W. Putnam, M.D., Charles G. Halgrimson, M.D., Lawrence Koep, M.D., and \\ Thomas E. Starzl, M.D., Ph.D.
}

Departments of Surgery, Veterans Administration Hospital and University of Colorado Medical Center, Denver. Colorado, U.S.A.

Since the first clinical orthotopic liver transplant was performed 13 years ago, approximately 275 patients have undergone this procedure. The Denver series constitutes about $40 \%$ of this total experience. In our series, the overall 1-year survival has been $29 \%$; the longest survivor is now $62 / 3$ years posttransplantation. Most of the early deaths have been caused by technical complications, frequently related to difficulties in establishing and maintaining adequate biliary drainage. The late deaths have been from a variety of causes, including recurrent tumor, hepatitis, bile duct obstruction, and chronic rejection.

Favorable indications for liver transplantation include biliary atresia, chronic aggressive hepatitis, inborn errors of metabolism, and certain other benign hepatic diseases. Alcoholic cirrhosis is a less favorable indication and primary hepatic malignancy is a relative contraindication. The immunologic criteria for donor-recipient selection are much less rigid than for renal transplantation.

Biliary reconstruction is the principal technical problem encountered with orthotopic liver transplantation. Guidelines for the establishment of biliary drainage, its evaluation, and the management of postoperative biliary complications are discussed.

The first orthotopic liver transplant in man was performed on March 1, 1963 at the University of Colorado [1]. Since then, approximately 275 patients have been treated with this procedure throughout the world. The Denver series now includes 114 patients or about $40 \%$ of the total experience. The second

Supported by research grants MRIS 8118-01 and 7227-01 from the Veterans Administration: by United States Public Health Service Grants AM-17260 and AM-07772; and by Grants R R-00051 and R R. -00069 from the General Clinical Research Centers Program of the Division of Research Resources, National Institutes of Health.

Reprint requests: Charles W. Putnam. M.D.. Department of Surgery, University of Colorado Medical Center, 4200 East Ninth Avenue, Denver, Colorado 80262. U.S.A. most active group in the field has been composed of personnel at Addenbrooke's Hospital, Cambridge, and at King's College Hospital, London. The British inter-university effort has involved the fruitful collaboration of the surgeon. Professor Roy Calne, and the gastroenterologist, Professor Roger Williams, and has resulted in approximately 50 orthotopic liver transplantations. The numerous and important contributions [2-4] from the United Kingdom group should be perused by anyone deeply interested in this subject.

Six months ago, we described in detail the results in our first 93 cases [5]. In this article, we will discuss our present views regarding liver transpla'tation based largely on the conclusions of that report, emphasizing our results with the procedure, the question of candidacy for liver transplantation, and certain technical problems that have been encountered, particularly the problem of biliary reconstruction.

Results of Liver Transplantation: University of Colorado Series

Of the 114 patients in the University of Colorado series, 103 were transplanted a year or more ago. Thirty of them, or $29 \%$, have survived for at least 1 year after liver replacement (Table 1). In recent years, the 1-year survival figures have been generally somewhat better, fluctuating in the 25 to $45 \%$ range.

If this heavy early mortality were to continue after the first year, there would be significant cause to question the validity of the procedure. Fortunately, most of the patients who reach the 1-year mark continue to do well thereafter. For example, half of all our 1-year survivors are still alive. A total of 15 patients have reached the 2 -year mark, 8 have reached 3 years, and 4 are 5 -year survivors (Table 1 ). The longest survivor in our series (and in the world) 
Table 1. Survival after liver transplantation at the University of Colorado

\begin{tabular}{|c|c|c|c|c|c|c|c|}
\hline & \multirow[b]{2}{*}{ No. } & \multicolumn{6}{|l|}{ Lived } \\
\hline & & 1 year & 2 years & 3 years & 4 years & 5 yedrs & $\begin{array}{l}\text { Alive } \\
\text { now }\end{array}$ \\
\hline $1963-1966$ & 6 & 0 & 0 & 0 & 0 & 0 & 0 \\
\hline 1967 & 6 & 1 & 0 & 0 & 0 & 0 & 0 \\
\hline 1968 & 12 & 5 & 2 & 1 & 0 & 0 & 0 \\
\hline 1969 & 6 & 2 & 1 & 1 & 1 & $1^{*}$ & 0 \\
\hline 1970 & 10 & 2 & 1 & 1 & 1 & 1 & 1 \\
\hline 1971 & 11 & 2 & 2 & 2 & 2 & 2 & 2 \\
\hline 1972 & 11 & 5 & 3 & 2 & 2 & 0 & 2 \\
\hline 1973 & 13 & 3 & 3 & 1 & 0 & 0 & 2 \\
\hline 1974 & 20 & 8 & 3 & 0 & 0 & 0 & 6 \\
\hline \multirow[t]{2}{*}{1975} & 8 & 2 & 0 & 0 & 0 & 0 & 2 \\
\hline & $\overline{103}$ & 30 & 15 & 8 & 6 & 4 & 15 \\
\hline
\end{tabular}

Only patients at risk for 1 year are included.

* Died after $511 / 12$ years.

- Alive $62 / 3$ years.

is now $62 / 3$ years post-transplantation. She is living at home, attending school, and has normal liver function. Two other 5-year survivors are also entirely well, but the fourth one died a few days short of the 6year mark of chronic rejection and partial biliary obstruction.

The causes of death after 1 year are given in Table 2. In retrospect, at least some of these late deaths might have been avoided, either by better patient selection (in the case of recurrent tumor) or by improved management, particularly of biliary tract problems.

\section{Selection of Candidates for Liver Transplantation}

\section{Influence of Age}

Not surprisingly, younger patients have had a better prognosis after liver transplantation than older ones; for patients over 40 years of age, the 1-year survival has been less than $10 \%$. The much increased mortality in the older recipients has largely been the consequence of pulmonary or other infectious complications, problems with maintaining adequate nutrition, or neurologic complications. We believe that candidacy for this formidable undertaking generally should be limited to those under 45 years of age, and

Table 2. Present status of 30 one-year survivors of liver transplantation

\begin{tabular}{lll}
\hline Alive $15 / 30$ & - & 12 months to 80 months \\
Dead $15 / 30$ & - & 12 months to 71 months \\
& Recurrent cancer-4 \\
& Chronic rejection-5 \\
& Chronic hepatitis-2 \\
& Bile duct \\
obstruction-2 & \\
& Other infections-2 \\
\hline
\end{tabular}

that potential recipients toward the upper end of this spectrum should be carefully evaluated preoperatively.

\section{Influence of the Original Hepatic Disease}

Primary Hepatic Malignancies. A number of the early recipients of liver homografts were transplanted for nonresectable hepatic malignancies, such as hepatoma, cholangiocarcinoma, or hemangioendothelial sarcoma. Of our 12 patients in this category, 7 died soon after transplantation of complications not related to their malignancy. The other 5 patients, however, all developed tumor recurrence and died from 87 to 432 days after transplantation. Widespread metastases were found at autopsy, and, interestingly, the homograft livers almost always contained tumor.

Because of this proclivity to develop tumor recurrence after transplantation, we view patients with large, nonresectable primary hepatic malignancies as highly questionable candidates for liver replacement. Exceptions to this policy have been made if a tumor is an incidental finding in a liver afflicted with another disease. For example, one of our recipients with biliary atresia also had a small hepatoma in the excised specimen. Not only has she had no evidence of tumor recurrence, but she is our longest survivor after liver transplantation.

Initially we thought the so-called Klatskin tumors [6], duct cell carcinomas arising at the bifurcation of the hepatic ducts, might be an exceptionally good indication for liver transplantation. These tumors, because of their strategic location, usually become symptomatic while still quite small and usually kill by obstruction rather than by widespread disease. Four patients with this malignancy have been treated by liver replacement. Two died early after operation. The other 2 patients survived 2 years postoperatively: 


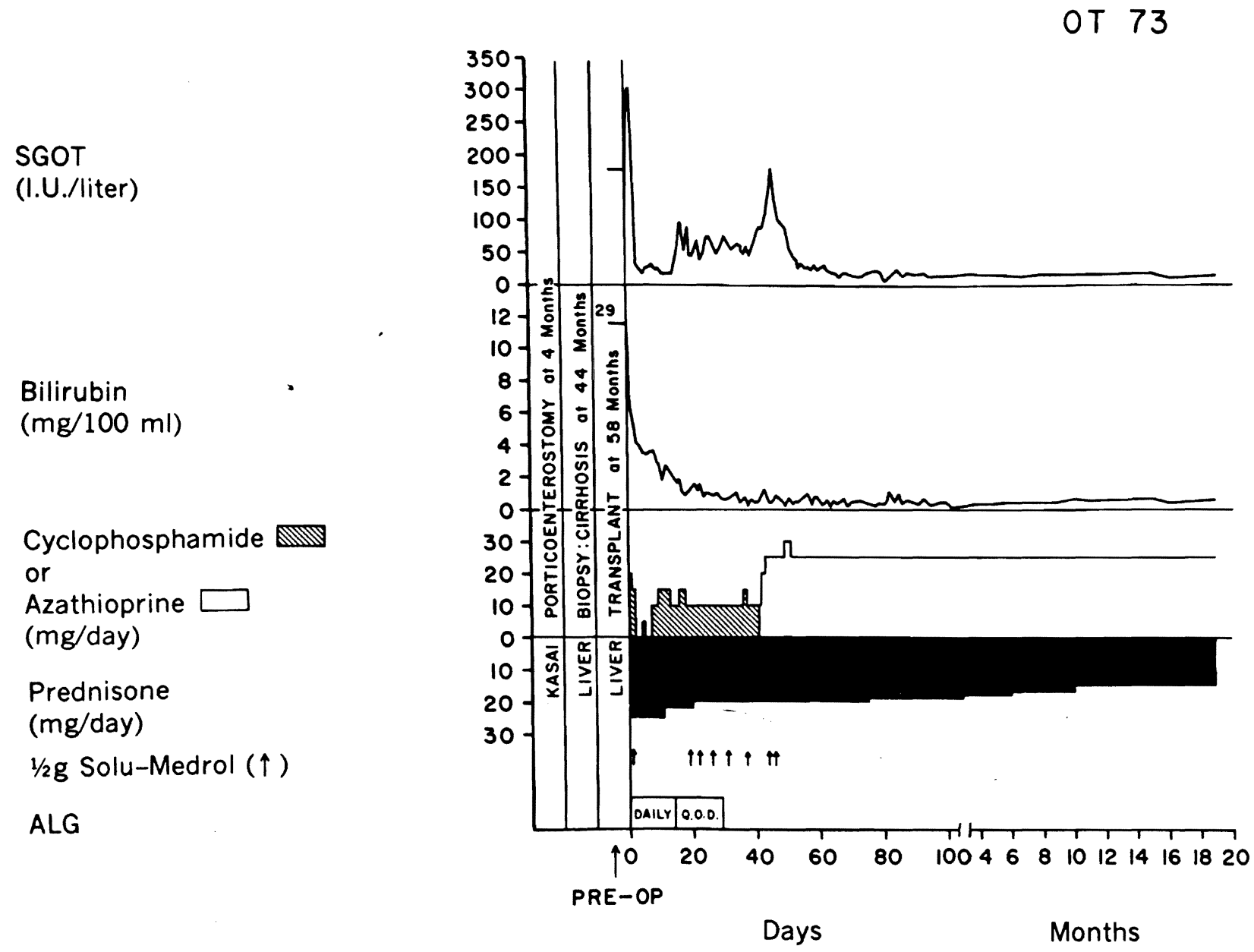

Fig. 1. The course of a child who had a failed Kasai operation but who ultimately was effectively treated with liver replacement. (From ref. 7 with permission.)

1 died at that time of recurrent tumor in his transplanted liver, and the other is alive and clinically free of recurrent malignancy. Although the long-term prognosis in such cases is still in doubt, further trials in younger patients are certainly warranted.

Biliary Atresia. Children with biliary atresia are generally good candidates for liver transplantation. These patients usually enjoy relatively good health until late in the course of the disease and their livers often retain adequate synthetic function. In individual cases, however, it may prove difficult or even impossible to revascularize the homgoraft livers, either because of congenital anomalies of the hepatic blood supply, which are not uncommon in patients with biliary atresia, or because of technical problems posed by the small size of the vessels. The latter difficulties have largely been overcome by employing $\mathrm{mi}$ crosurgical techniques in reconstructing the hepatic blood supply.

Several of our patients transplanted for biliary atresia have had prior Kasai porticoenterostomy procedures. The previous operative intervention has not precluded successful transplantation [7], and in sev- eral cases the Kasai procedure has successfully "bought time" for the patient, thus lengthening the period of potential candidacy for transplantation (Figure 1). This is obviously of particular importance in these youngsters for whom potential donors are few and far between.

Alcoholic Cirrhosis. The results of transplantation for alcoholic cirrhosis have been much less satisfactory. Of 11 such patients transplanted so far, only 1 , a former professional football player, has achieved longterm survival. Another patient is alive less than 2 months after the procedure. If the patient has repudiated the use of alcohol, there should be no intrinsic contraindication to his candidacy. In practice, the uncertain course of this disease has frequently resulted in procrastination in referring patients for the procedure. By the time of referral, one or more complications has usually supervened. Most commonly, gastrointestinal bleeding, pneumonitis or other infectious complications, or hepatic encephalopathy are present, thereby severely jeopardizing the chances for recovery. Improvement in the results after transplantation in this group of candidates will require 
that these patients be referred for transplantation before these complications arise.

Chronic Aggressive Hepatitis. Postnecrotic cirrhosis or chronic aggressive hepatitis are favorable indications for transplantation. Patients with these diseases are usually younger than those with alcoholic cirrhosis and the downhill course of their disease is generally more predictable. If the hepatitis B antigen is not present preoperatively, the recipient does not seem to be at significant risk of developing recurrent hepatitis postoperatively. When antigenemia predates transplantation, antigen-positive hepatitis postoperatively may prove to be a major threat. Indeed, one of our patients who was transplanted for this indication developed acute antigen-positive hepatitis postoperatively, which progressed to chronic aggressive hepatitis from which she eventually died [8]. Retrospective analysis of serum samples during the early postoperative period showed that trace amounts of the antigen were still present and probably caused infection of the homograft liver. Two patients with antigen-positive hepatitis treated subsequently have received high-titer anti- $\mathrm{HB}_{\mathbf{s}} \mathrm{Ag}$ antiserum intra- and postoperatively. This therapy appeared to be successful in eliminating the residual serum antigen remaining after removal of the infected liver. Unfortunately, both patients died early after operation, 3 and 7 weeks post-operatively, before clinical hepatitis could be expected to appear. Thus, the effectiveness of antiserum therapy in preventing the subsequent occurrence of hepatitis will be determined only by further trials.

Inborn Errors of Metabolism. Our best results with liver transplantation have been in patients with hepatic-based inborn errors of metabolism. We have treated 3 such diseases: Wilson's disease, alpha ${ }_{1}$-antitrypsin deficiency, and tyrosinemia. In addition, Daloze, Corman and their associates in Montreal [9] have successfully transplanted a patient with Niemann-Pick disease.

In Wilson's disease, there is progressive accumulation of copper in the body. The characteristic KayserFleischer rings are an external manifestation of this, representing discoloration of the corneas by the metal deposits. More importantly, deposition of copper in the liver and brain may cause subsequent degenerative changes. We have treated 2 children for this disorder $[10,11]$. Both survived for 5 years after transplantation: one is alive and entirely well, but the other died of chronic rejection and partial biliary obstruction unrelieved by late reoperation. Metabolic studies in these patients showed that the copper-containing ceruloplasmin, which was low or virtually absent preoperatively, became normal postoperatively. There was a prolonged cupriuresis postoperatively, which reduced the tremendously elevated total body copper content. Neither of the homografts showed any tendency to reaccumulate the metal. One of the patients had severe neurologic impairment preoperatively which gradually improved after transplantation, becoming normal over the next 3 years.

Alpha $a_{1}$-antitrypsin deficiency is a hereditary disease which predisposes to congenital infantile cirrhosis [12] and occasionally adult cirrhosis, as well as pulmonary emphysema of early onset in adults. The homozygous $\mathrm{Pi}^{\mathrm{ZZ}}$ phenotype is not terribly rare; its incidence is estimated to be about 1 in 2,500 live births. Approximately 20 to $30 \%$ of children who have this phenotype will develop cirrhosis [12].

In November, 1973, we transplanted a 16-year-old girl with cirrhosis caused by alpha ${ }_{1}$-antitrypsin deficiency, $\mathrm{Pi}^{\mathrm{zz}}$ phenotype [13]. Postoperatively, she developed normal levels of alpha ${ }_{1}$-antitrypsin which had the donor phenotype, $\mathrm{Pi}^{\mathrm{MM}}$ (Table 3 ). Two years after transplantation her graft failed from chronic rejection. A second transplantation was performed, the donor for which by coincidence had the heterozygous $\mathrm{Pi}^{\mathrm{MZ}}$ phenotype and a correspondingly reduced serum alpha ${ }_{1}$-antitrypsin concentration (heterozygotes, however, have no predilection to develop liver disease). Following retransplantation the recipient again adopted the donor's phenotype, this time $\mathrm{Pi}^{\mathrm{MZ}}$ (Table $3)$. Unfortunately, the patient died a month later of pulmonary infection, but the validity of the metabolic correction by liver transplantation was established.

Daloze, Corman, and their associates [9] have treated a 2-year-old child with Niemann-Pick disease. In this disorder, deposits of sphingomyelin within the liver cause hepatic failure. After transplantation, the homograft liver showed no tendency to reaccumulate sphingomyelin, and sphingomyelinase, the deficient enzyme, could be found in normal concentrations in the blood, urine, cerebrospinal fluid, and the graft itself. Unfortunately, there was severe neurologic impairment preoperatively which did not improve after transplantation and the child died of respiratory complications 2 years later.

The fourth inborn error of metabolism which has been treated by liver transplantation is tyrosinemia. Two months ago we transplanted a 10 -year-old child with this disorder who also had a multifocal hepatoma within her severely cirrhotic liver. Postoperatively, the serum and urine tyrosine concentrations rapidly became normal and the urinary excretion of $p$-hydroxyphenyl pyruvic acid products gradually declined. These findings suggest that this disorder was corrected by transplantation; further metabolic studies are now in progress.

Other Benign Hepatic Diseases. Prolonged survival has been achieved after liver replacement in patients with primary biliary cirrhosis and the Budd-Chiari syndrome [14]. However, we have not yet successfully 
Table 3. Serum alpha ${ }_{1}$-antitrypsin concentration and phenotypes before and after liver transplantation

\begin{tabular}{|c|c|c|c|c|c|c|}
\hline & \multirow[b]{2}{*}{ Pretransplant } & \multirow{2}{*}{$\begin{array}{l}\text { First } \\
\text { donor }\end{array}$} & \multicolumn{2}{|c|}{ Post-transplant } & \multirow{2}{*}{$\begin{array}{l}\text { Second } \\
\text { donor }\end{array}$} & \multirow{2}{*}{$\begin{array}{l}\text { After } \\
\text { retransplant }\end{array}$} \\
\hline . & & & 18 months & 27 months & & \\
\hline $\begin{array}{l}\text { Phenotype } \\
\text { Enzyme Concentration }(\mathrm{mg} \%) \\
\text { (normal } 140-470)\end{array}$ & $\begin{array}{l}\mathrm{ZZ} \\
55\end{array}$ & $\begin{array}{c}\mathrm{MM} \\
-\end{array}$ & $\begin{array}{r}\mathrm{MM} \\
264\end{array}$ & $\begin{array}{l}\text { MM } \\
256\end{array}$ & $\begin{array}{l}M Z \\
176\end{array}$ & $\begin{array}{l}M Z \\
270\end{array}$ \\
\hline
\end{tabular}

treated patients with acute liver failure from fulminant hepatitis or other toxic agents, largely because of the logistic problems in obtaining an appropriate cadaveric organ during the brief time span in which such patients are satisfactory candidates for transplantation.

\section{Criteria for Donor-Recipient Selection}

Since no artificial support system comparable to hemodialysis is available to potential recipients of liver transplants, their period of candidacy is necessarily much shorter than that of patients with endstage renal disease. Therefore, a relaxation of criteria for donor-recipient selection is necessary if they are to be treated at all. Indeed, if the pace of deterioration of the recipient warrants doing so, all ordinary immunologic restrictions may be ignored and an $A B O$-incompatible or crossmatch-positive organ inserted. Under less pressing circumstances, of course, the guidelines described below are observed.

$A B O$ Compatibility. The rules for $\mathrm{ABO}$ matching of donor to recipient are identical to those used for transplantation of other organs, such as the kidney. If these barriers are violated in renal transplantation, hyperacute rejection of the organ is the usual although not invariable consequence. This does not appear to be the case after liver transplantation, since 7 of our patients have received such ABO-incompatible organs without any evidence of hyperacute rejection. However, it is not yet clear whether these organs may be more susceptible to late rejection than ABO-compatible ones.

Cytotoxic Antibody Crossmatch. Hyperacute rejection of renal homografts is also an extremely common occurrence if the recipient possesses preformed cytotoxic antibodies against donor cells. Again, the liver is quite resistant to this immunologic complication: the fate of hepatic homografts placed in such an immunologically hostile environment does not seem to be any different than in crossmatch-negative cases.

HL-A Typing. Although HL-A typing is routinely performed, the results are not used to guide the selection of donor-recipient pairs. As a consequence of this policy, most of the HL-A matches have been poor ones (Table 4). With such a skewed spectrum of histocompatibility, conclusions about the predictive validity of the technique cannot be drawn. Clearly, there is no definable correlation between the quality of match and survival in this limited series (Table 4).

\section{Techniques of Orthotopic Liver Transplantation}

The vascular reconstruction of the orthotopic liver homograft has largely become standardized. The graft vena cava is anastomosed to the analogous host vessels above and below the liver. The portal vein of the graft is anastomosed end-to-end to the host portal vein, and the hepatic artery is usually revascularized with the common hepatic artery of the recipient (Figure 2).

Most of the technical problems with this procedure have arisen from failure to maintain satisfactory biliary drainage. Until 1973, biliary reconstruction was usually with cholecystoduodenostomy (Figure $2 A)$. The weak link of this technique is the cystic duct, which becomes obstructed in about one-third of the cases in which the gallbladder is used for anastomosis. In the first few cases in which this occurred, the correct diagnosis was not made until autopsy. Subsequently, several cases were diagnosed during life by operative cholangiography, but reoperation was still usually too late. In 1973, a policy of per-

Table 4. HL-A typing of primary hepatic grafts in 103 cases

\begin{tabular}{lrl}
\hline Match* & No. & $\begin{array}{l}\text { Survival } \\
1 \text { year }\end{array}$ \\
\hline A & 1 & $1^{+}$ \\
B & 3 & $1(33 \%)$ \\
C & 15 & $3(20 \%)$ \\
D & 27 & $5(19 \%)$ \\
E & 44 & $16(36 \%)$ \\
F & 6 & $1(17 \%)$ \\
Not done & 7 & $1(14 \%)$ \\
$\quad$ Total & 103 & $28(29 \%)$ \\
\hline
\end{tabular}

* A match, HL-A identity between recipient and donor; B match, compatibility between donor and recipient, but fewer antigens determined in the donor; $\mathrm{C}$ match, one antigen incompatible: $D$ match. two antigens incompatible: $E$ match, three or four antigens incompatible; $F$ match, $A B O$ violation or positive crossmatch to cytotoxic antibodies.

- Retransplanted after 68 days with C-match graft. Thus, the l-year survival was due mainly to the second, less well matched organ. 

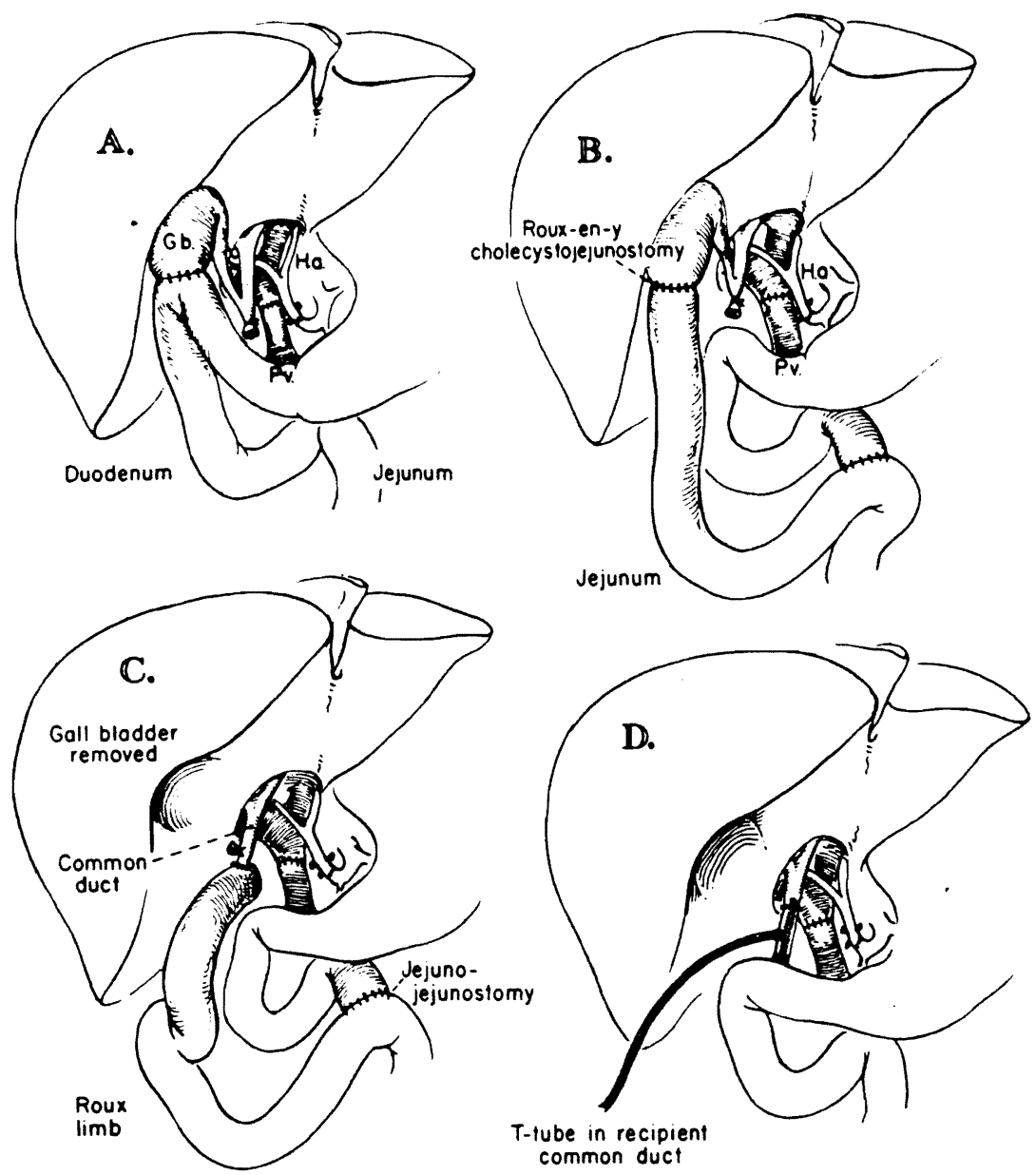

Fig. 2 A-D. Techniques of biliary duct reconstruction used for most of the transplantation recipients. A. Cholecystoduodenostomy. B. Cholecystojejunostomy. C. Choledochıjejunostomy after removal of gallbladder. D. Choledochocholedochostomy. Note that the T-tube is placed, if possible, in recipient common duct. (From ref. 5 with permission.) forming transhepatic cholangiography whenever recurrent jaundice appeared was adopted. For this study, the very thin needle developed in Chiba, Japan, was used. This technique proved to be quite safe and immensely helpful.

At about the same time, an appreciation of the role of hepatic sepsis in these cases led to the adoption of Roux-en-y biliary drainage to avoid gastrointestinal contamination of the biliary system. The strategy that evolved was to perform cholecysto-Roux-en-y-jejunostomy (Figure 2B) as the primary reconstruction. If jaundice reappeared and transhepatic cholangiography confirmed cystic duct obstruction, the gallbladder was removed and a choledochojejunostomy created (Figure 2C). Alternative techniques which share the advantage of placing the biliary system out of the direct continuity with the gastrointestinal tract include choledochocholedochostomy with T-tube drainage (Figure 2D) and primary choledochojejunostomy.

It is apparent that no one technique of biliary reconstruction will be satisfactory for all patients; each case must be individualized. Certain principles of reconstruction, however, have emerged. Ideally, the biliary reconstruction should avoid using the cystic duct with its inherently high risk of obstruction. Secondly, the liver should be protected from the bacterially contaminated gastrointestinal contents either with a defunctionalized Roux-en-y limb of jejunum or by the sphincter of Oddi. Thirdly, radiographic visualization of the biliary tree, either by tube cholangiography or by the transhepatic approach, must be obtained whenever jaundice reappears after transplantation. Finally, if obstruction is detected, prompt reoperation is vital.

\section{Future Prospects}

The procedure of orthotopic liver transplantation is a formidable one, particularly when the patient has significant portal hypertension and a major coagulopathy. Moreover, problems with biliary reconstruction have plagued this venture during its infancy and, indeed, continue to do so. The necessary preoccupation with the technical requirements of liver replacement has obscured the fact that rejection has been much less of a problem [5] than after cadaveric renal homotransplantation. Yet only by the precise management of technical details will the benefits afforded by this immunologic advantage be accrued. Despite this advantage, liver homografts will still be 
lost from rejection. Rather than pursuing aggressive immunosuppression in an attempt to prolong graft survival, investigators may have to show a greater willingness to accept the need for retransplantation, despite the obvious technical obstacles.

\section{Résumé}

La première transplantation orthotopique du foie chez l'homme a été faite il y a 13 ans. Depuis, environ 275 patients ont bénificié de cette opération et $40 \%$ d'entre eux ont été opérés à Denver. Dans notre série, $30 \%$ des patients ont survécu au moins 1 an. La plus longue survie est actuellement 6 ans $2 / 3$. Les problèmes techniques ont été responsables de la plupart des décès à court terme. Quant aux décès tardifs, ils ont été causés par une variété de complications incluant la récidive de tumeur, l'hépatite, l'obstruction des voies biliaires et les phénomènes de rejet chronique. Les pathologies bénignes du foie, en particulier l'atrésie des voies biliaires, l'hépatite chronique active et les erreurs innées du métabolisme constituent les indications les plus favorables. La cirrhose alcoolique a été associée à des résultats moins encourageants tandis que les tumeurs maligne primitives du foie constituent une contre-indication relative. Les critères immunologiques pour la sélection des donneurs sont moins rigides que pour la transplantation rénale. Le principal problème technique rencontré lors des transplantations orthotopiques du foie a été celui de la reconstruction des voie biliaires. Les auteurs joignent à ce rapport une discussion détaillée portant sur ce sujet.

\section{References}

1. Starzl, T.E., Putnam, C.W.: Experience in Hepatic Transplantation. Philadelphia, W.B. Saunders Co., 1969

' 2. Calne, R.Y., Williams, R., Dawson, J.L., Ansell, I.D., Evans, D.E., Flute, P.T., Herbertson, P.M., Joysey, V., Keates, G.H.W., Knill-Jones, R.P., Masow, S.A., Millard, P.R., Pena, J.R., Pentlow, B.D., Salaman, J.R.,
Sells, R.A., Cullum. P.A.: Liver transplantation in man. II. A report of two orthotopic liver transplants in adults recipients. Br. Med. J. 4:541, 1968

3. Williams, R., Smith, M.. Shilkin, K.B., Herbertson, B.. Joysey, V., Calne, R.Y.: Liver transplantation in man: the frequency of rejection. biliary tract complications, and recurrence of malignancy based on an analysis of 26 cases. Gastroenterology 64:1026, 1973

4. Calne, R.Y.: Clinical and experimental liver grafting. Guys Hosp. Rep. 123:1. 1974

5. Starzl, T.E., Porter, K.A., Putnam, C.W., Schroter, G.P.J., Halgrimson. C.G., Weil, R., III, Hoelscher, M.. Redi, H.A.S.: Orthotopic liver transplantation in ninety-three patients. Surg. Gynecol. Obstet. 142:487. 1976

6. Klatskin, G: Adenocarcinoma of the hepatic duct at its bifurcation within the porta hepatis: an unusual tumor with distinctive clinical and pathological features. Am. J. Med. 38:241, 1965

7. Starzl, T.E., Porter, K.A., Putnam, C.W., Beart, R.W., Halgrimson, C.G., Gadir, A.F.A.: Liver replacement in children. Proceedings of the Josiah Macy, Jr., Foundation International Conference on Liver Disease in Infancy and Childhood, June 26-28, 1975 (in press)

8. Corman, J.L., Putnam, C.W., Iwatsuki, S., Redeker, A.G., Porter, K.A., Peters, R.L., Schroter, G., Starzl, T.E.: Liver homotransplantation for chronic aggressive hepatitis, Australia antigen positive. Gastroenterology (in press)

9. Daloze, P., Corman, J.. Bloch, P., Delvin, E.E., Glorieux, F.H.: Enzyme replacement in Niemann-Pick disease by liver homotransplantation. Transplant. Proc. 7:607, 1975

10. DuBois, R.S., Giles, G., Rodgerson, D.O., Lilly, J., Martineau, G., Halgrimson. C.G., Schroter, G., Starzl, T.E., Sternlieb, I., Sheinberg. I.H.: Orthotopic liver transplantation for Wilson's disease. Lancet $1: 505$, 1971

11. Groth, C.G., DuBois, R.S., Corman, J., Gustafsson, A., Iwatsukis. S., Rodgerson. D.O., Halgrimson, C.G., Starzl, T.E.: Metabolic effects of hepatic replacement in Wilson's disease. Transplant. Proc. 5:829, 1973

12. Sharp, H.L.: Alpha ${ }_{1}$-antitrypsin deficiency. Hosp. Prac. 6:83, 1971

13. Putnam, C.W., Porter, K.A., Peters, R.L., Ashcavai, M., Redeker, A.G., Starzl. T.E.: Liver replacement for alpha $\mathrm{a}_{1}$-antitrypsin deficiency. Surgery (in press)

14. Putnam, C.W., Porter, K.A.. Weil, R., Reid, H.A.S., Starzl, T.E.: Liver transplantation for the Budd-Chiari syndrome. J.A.M.A. 236:1142, 1976 


\section{INVITED COMMENTARY}

\author{
RoY Y. CALNE, F.R.S.
}

\section{Department of Surgery, Addenbrooke's Hospital Cambridge, England}

The work on liver grafting by the Denver group headed by Dr. Starzl has been outstanding. The review of this subject by Putnam et al. in this issue, based chiefly on the 114 patients treated in Denver since 1963, will be of great value to all interested in organ grafting. With a follow-up of more than a year for 103 of their cases and a $29 \%$ one year survival, the authors raise the central question on the validity of liver replacement as therapy. They point out that patients surviving a year usually continue to do well, $50 \%$ of their one year survivors being alive at present, with the longest surviving patient having normal liver function and living a full life 6.4 years after operation. I will comment on the main points raised in

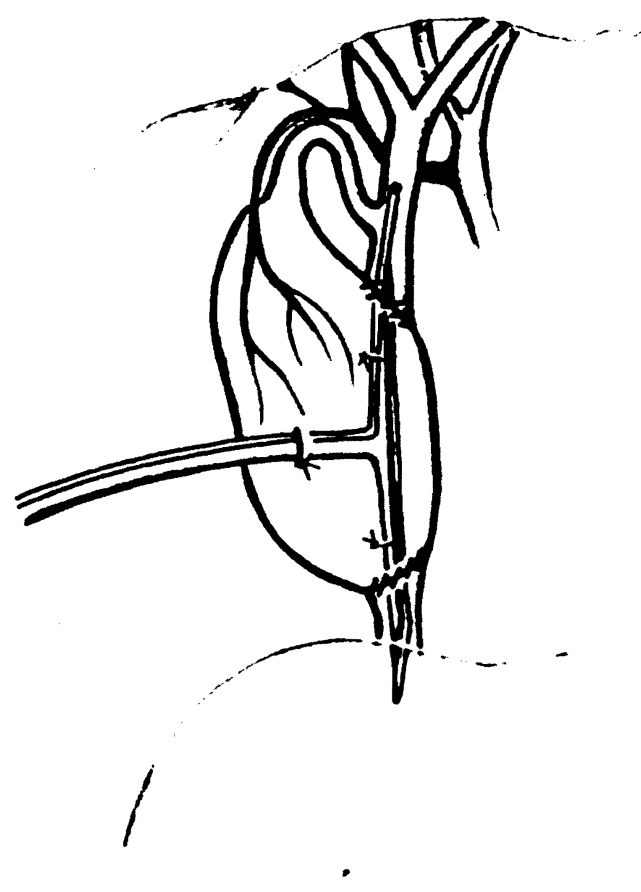

Fig. 1. Diagram of pedicle graft conduit with the donor gall bladder. Hartmann's pouch is anastomosed to the donor common duct and the fundus anastomosed to the recipient common duct. An irrigating T-tube is inserted with the irrigating arm through the upper anastomosis. Blood supply to the gall bladder is carefully preserved. (By courtesy of the British Medical Journal). their article from the standpoint of an experience of 57 orthotopic liver allografts performed in the Cambridge/King's College Hospital series [1].

\section{Indications}

I am sure that the Denver group are correct in aiming at liver grafting in young patients, but I would not set an absolute upper age limit, but rather consider the patient's "biological" age. Moreover, although excellent results have been obtained in infants and very young children, I am reluctant to inflict this formidable procedure-not just the operation, but also the intensive pre- and postoperative surveillance and treatment-on a child who cannot understand the necessarily guarded prognosis that can at present be offered.

I would agree that recurrence of primary malignancies can be expected in about $75 \%$ of cases, but some patients are cured and many are palliated as well as can be achieved by comparable treatment of many malignant growths treated by conventional surgery. My feelings concur with those of the authors on the other indications for liver grafting and we have additional data on Australia antigenemia. One of our patients with a primary hepatoma and antigenemia, treated with high titer antiserum following hepatectomy, has remained antigen negative more than 6 months after grafting.

\section{Donor Selection}

Although we have not transgressed $A B O$ incompatibility in our cases, we have transplanted a liver in the face of a donor specific, strongly positive cross-match without untoward effect. We have also found the liver to be much less susceptible to rejection than the kidney, and in the past it is likely that many of our patients have died from the side effects of excessive immunosuppressive treatment. Unlike the Denver group we have never used antilymphocyte globulin, yet the incidence of uncontrollable rejection in our series has been comparable to the Denver cases, i.e. under $10 \%$.

\section{Technical Considerations}

We have followed the principles laid down by the Denver group, but in view of the extreme shortage of donor organs, we have extended our donor catchment area by use of simple flush cooling of the liver and storage in ice. Sixteen livers taken from donors in institutions up to 400 miles away have all functioned well immediately following revascularization, despite the period of cold ischemia having been extended to more than 8 hours [2]. 
Fig. 2. Diagram of the use of the vascularized gall bladder as a conduit between the donor common duct and a long Roux loop of jejunum in a patient whose own common duct could not be used. Hartmann's pouch is anastomosed to the common bile duct of the donor and the fundus of the gall bladder to the Roux loop. (By courtesy of the British Medical Journal).

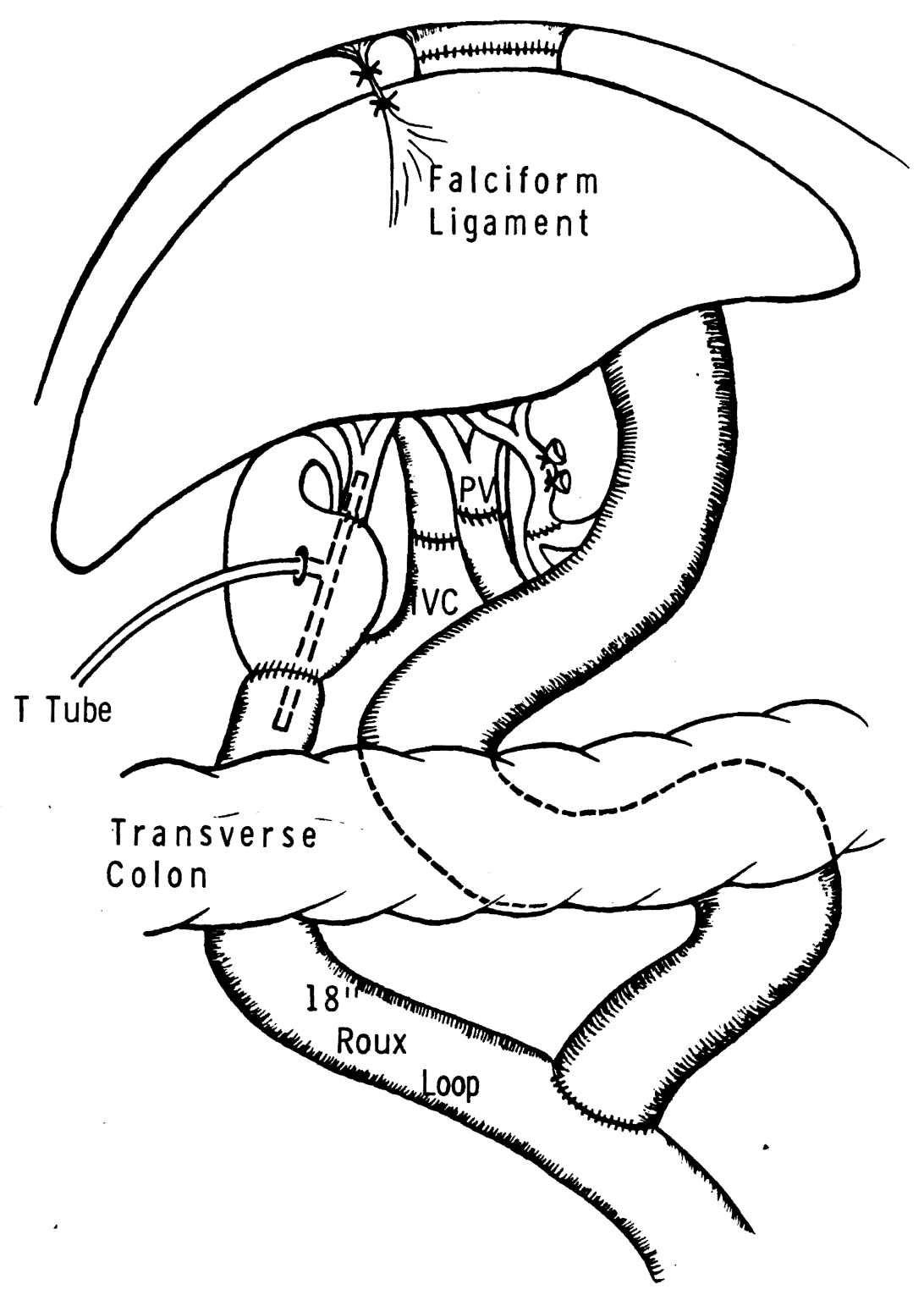

\section{Biliary Drainage}

- We were also plagued by an unacceptably high incidence of fatal complications of biliary drainage occurring in more than 50 of our cases. Many varieties of technique were used but one or more of the weak points mentioned by Putnam et al. were unavoidable with all conventional procedures. In the last 18 months $I$ have been using a new technique involving the vascularized gall bladder as a conduit between donor and recipient common duct [4] (Fig. 1). The anastomoses are splinted with a special $\mathrm{T}$ tube with an irrigating arm threaded through the proximal anastomosis, through which heparinized saline solution is infused in the early postoperative period to prevent biliary sludge accumulating. This form of bile drainage has been used in 17 cases as a primary procedure and 2 as a secondary operation following breakdown of duct-10-duct anastomoses. The sphinc- ter of Oddi is preserved, wide anastomoses with good blood supplies are possible, there is no bile duct sump for accumulation of sludge and there is ready access to the biliary ducts for radiography. Although the follow-up period is short, in each patient biliary drainage has been initially satisfactory and the incidences of biliary leakage and anastomotic stenosis have been markedly reduced. In one patient in whom the recipient common duct could not be used, the technique was modified by anastomosing the fundus of the gall bladder conduit to a long Roux loop (Fig. 2).

We agree with Putnam et al. on the validity of liver grafting as a form of therapy. Our experience of the excellent quality of life in patients with liver allografts discharged from hospital encourages us to continue. One of our patients survived 5.4 years, dying suddenly of cholangitis following blockage of bile drain- 
age. At autopsy there was no evidence of recurrent hepatoma, her original disease, nor were there signs of rejection. Currently 12 of our patients are alive, the longest after 3 years.

\section{References}

1. Caline, R.Y.. Williams, R.: Orthotopic liver transplantation: observations on the first fifty-seven patients. Br. Med. J.. In press

2. Wall, W.J., Calne, R.Y., Herbertson, B.M., Baker, P.G., Smith, D.P., Underwood, J.: Simple hypothermic preservation for transporting human livers long distances for transplantation: report of 12 cases. Transplantation. In press

\section{INVITED COMMENTARY}

\author{
JOSEPH G. FORTNER, M.D. \\ Transplantation Service, Memorial Sloan-Kettering \\ Cancer Center
}

New York, New York, U.S.A.

The contributions of Dr. Starzl and his colleagues to organ transplantation in general, and liver transplantation in particular, are monumental. This report is particularly encouraging in that about one-third of patients receiving an orthotopic liver transplant are reported to have lived for at least a year with markedly improved prospects for long-term survival thereafter. This survival rate has been achieved while exploring the feasibility of liver transplantation in patients who were terminally ill from a variety of diseases. Indeed, a great proportion would have been unlikely to survive even a minor operative procedure. With this experience, the authors are now able to better define the place of liver transplantation. Improved results are expected from better patient selection, more knowledgeable immune suppression, acceptance of the concept of retransplantation if graft rejection or other complications so indicate, and improved biliary-enteric connections.

The authors are justifiably concerned about total hepatectomy and orthotopic liver transplantation for the patient with primary liver cancer. Their experience here is limited to the individuals who survived transplantation; all developed recurrent cancer. These 5 appear to be patients who had extensive liver cancers which may have already spread before liver transplantation. Microscopic foci in regional lymph nodes or peritoneal seeding can be overlooked. Massive cancers in the liver are confined by the thin covering of Glisson's capsule. A biopsy or inadvertent tear of the capsule could contaminate the peritoneal cavity with tumor cells. Hepatocellular carcinomas often have tumor thrombi so that manipulations of the liver during its removal could dislodge these, leading to pulmonary metastases. It is important to realize that tumor recurrence in such cases is not necessarily due to immune suppression which must accompany organ transplantation. A low cure rate can be expected for extensive cancers treated by any method including transplantation. Better selection of patients will undoubtedly result in cures of individuals who have primary liver cancers.

The liver involved by cholangiocarcinoma lends itself much more readily to liver transplantation. Tumor thrombi occur less frequently than with hepatocellular carcinomas. The tumors tend to be less bulky and are commonly surrounded by a margin of normal liver tissue. Total hepatectomy and orthotopic liver transplantation appears to be an excellent way to treat cholangiocarcinomas involving both lobes of the liver.

The biliary-enteric anastomosis has been the Achilles heel of liver transplantation. We have advocated and practiced a Roux-en-Y end-to-side choldochojejunostomy for the past 4 years. The anastomosis is carried out using interrupted 4-0 sutures after fishmouthing the end of the normal sized common bile duct. A stent is not used. This approach presents no more technical difficulties than an arterial anastomosis. A small catheter or a tiny T-tube may be placed in the common hepatic duct for monitoring the contents of the bile and for carrying out cholangiograms in the event of development of jaundice. This procedure was first carried out in our liver transplants on 12/13/72 after demonstration in our previous patients that a cholecystenterostomy led to an unacceptable frequency of complications.

It is important to consider a heterotopic or auxiliary liver transplant as an alternative to the orthotopic transplant for patients with end-stage, non-cancerous liver disease. It is interesting that the risks of the orthotopic transplant are almost prohibitive after age 40 . The substantially lessened operative risks, stress and time of the heterotopic liver transplant are borne out by the fact that the first successful heterotopic transplant was performed in a 72-year-old woman. She lived for 8 months after the graft with a transplant which functioned excellently. The concluding statement in the paper of the need for a greater willingness to accept the concept of retransplantation for severely damaged liver grafts is particularly appropriate for the auxiliary liver. A malfunctioning auxiliary liver can be removed and the 
patient's diseased liver can function as a temporary support until a suitable donor is obtained. We have recently reported on 7 heterotopic liver transplants: 3 recipients had congenital biliary atresia, one had idiopathic cholestasis syrdrome, 2 patients had postnecrotic liver cirrhosis, and one patient had an intractable pruritis and jaundice secondary to localized and unresectable bile duct cancer. One patient is living and well 4 years after transplantation. One individual lived 8 months with a normally functioning graft and succumbed to infection in her own liver secondary to obstruction by the bile duct cancer. A third patient initially had an uneventful course when a rejection reaction developed. Minimal increase in immunosuppression led to pneuymocystis carinii infection and death at $31 / 2$ months. The liver had recovered from the rejection and was functioning quite well. These results provide a sound basis for considering the heterotopic (auxiliary) transplant as an alternative to the orthotopic transplant for patients with end-stage, non-cancerous liver disease.

\section{References}

1. Fortner, J.G., Beattie, E.J., Jr., Shiu, M.H., Kawano, N., Howland, W.S.: Orthotopic and heterotopic liver homografts in man. Ann. Surg. 172:23, 1970

2. Fortner, J.G., Balner, H., Wilson, C.B., Sichuk, G., Shiu, M.H., Kawano, N., Holmes, J.T., Javitt, N., Beattie. E.J., Jr.: Observations on prolonged immune suppression for human liver homografts. Tränsplantation 3:373, 1970

3. Fortner, J.G., Beattie, E.J., Jr., Shiu, M.H., Howland, W.S., Watson, R.C., Gaston, J.P., Benua, R.S.: Surgery in liver tumors. Cur. Prob. Surg. June, 1972

4. Fortner, J.G., Kinne, D.W., Shiu, M.H., Howland, W.S., Kim, D.K., Castro, E.B., Yeh, S.D.J., Benua, R.S., Krumins, S.: Clinical liver heterotopic (auxiliary) transplantation. Surgery $74: 739,1973$

5. Fortner, J.G., Shiu, M.H.: Organ transplantation and cancer. In Symposium on Surgical Oncology, The Surgical Clinics of North America, E.J. Beattie, Jr., M.D., editor, Philadelphia, W.B. Saunders Company, 1974, pp. 871-876

6. Fortner, J.G., Kim, D.K., Shiu, M.H., Yeh, S.D.J., Howland, W.S., Beattie, E.J. Jr.: Heterotopic (auxiliary) liver transplantation in man. Transpl. Proc., (In press) 